\title{
Fixed point theorem of Zamfirescus type in generalized cone metric spaces
}

\author{
O. K. Adewale*, B.V. Akinremi \\ University of Lagos, Lagos, Nigeria \\ *Corresponding author E-mail: adewalekayode2@yahoo.com
}

\begin{abstract}
In this paper we establish and prove the existence of Zamfirescus fixed point theorem in G-Cone Metric Spaces.The uniqueness is also shown.

Keywords: Cauchy sequence, complete $G$-cone metric spaces, complete symmetric $G$-cone metric spaces, $G$-cone metric spaces, unique fixed point.
\end{abstract}

\section{Introduction}

The importance of fixed point theorems cannot be overemphasized. The study of metric fixed point theory has been researched extensively in the past decades [4]. Different researchers have attempted to generalise the usual notion of metric space $(X, d)$ to extend the known metric space theorems in a more general setting. In 2004, Mustafa and Sims [7] introduced the generalised metric space as generalisation of the usual metric space $(X, d)$. Furthermore, Beg, Abbas and Nazir [3], introduced the concept of $G$ - cone metric space by replacing the set of real numbers by ordered Banach space. The authors in [3] also introduced new fixed point theorems in this new structure.

\section{Preliminary notes}

We briefly give some basic definitions of concepts which serves as background to this work.

Definition $1.1[\mathbf{1}, \mathbf{4}]$. Let $X$ be a non-empty set. Suppose that $d: X \times X \rightarrow E$ satisfies:

(i) $0 \leq d(x, y) \forall x, y \in X$ and $d(x, y)=0$ if and only if $x=y$,

(ii) $d(x, y)=d(y, x) \forall x, y \in X$,

(iii) $d(x, y) \leq d(x, z)+d(z, y) \forall x, y, z \in X$.

Then $d$ is called a cone metric on $\mathrm{X}$ and $(X, d)$ is called a cone metric space.

Definition $1.2[6]$. Let $X$ be a non-empty set and $G: X \times X \times X \rightarrow[0, \infty)$ be a function satisfying the following properties:

(i) $G(x, y, z)=0 \quad$ if and only if $x=y=z$

(ii) $G(x, x, y)>0, \quad \forall x, y \in X$, with $x \neq y$

(iii) $G(x, x, y)<G(x, y, z), \quad \forall x, y, z \in X$, with $z \neq y$

(iv) $G(x, y, z)=G(p(x, y, z))$ (symmetry). Where $p$ denotes the permutation function. 
(v) $G(x, y, z) \leq G(x, a, a)+G(a, y, z) \quad \forall a, x, y, z \in X$ (rectangle inequality)

Then the function $G$ is called a $G$-metric.

Definition $1.3[3]$. Let $X$ be a non-empty set. Suppose that $d: X \times X \times X \rightarrow E$ satisfies:

1. $\left(G_{1}\right) G(x, y, z)=0$ if $x=y=z$,

2. $\left(G_{2}\right) 0<G(x, x, y)$; whenever $x \neq y \forall x, y \in X$,

3. $\left(G_{3}\right) G(x, x, y) \leq G(x, y, z)$; whenever $y \neq z$.

4. $\left(G_{4}\right) G(x, y, z)=G(x, z, y)=G(y, x, z)=\ldots$ (Symmetric in all the three variables),

5. $\left(G_{5}\right) G(x, y, z) \leq G(x, a, a)+G(a, y, z) \forall x, y, z, a \in X$.

Then $G$ is called a generalized cone metric on $\mathrm{X}$ and $X$ is called a generalized cone metric space or $G$-cone metric space.

Definition 1.4 [3]. A $G$-cone metric space $X$ is symmetric if $G(x, y, y)=G(y, x, x) \forall x, y \in X$.

Proposition 1.5 [3]. Let $X$ be a $G$-cone metric space, define $d_{G}: X \times X \rightarrow E$ by $d_{G}(x, y)=G(x, y, y)+G(y, x, x)$. Then $\left(X, d_{G}\right)$ is a cone metric space. It can be noted that $G(x, y, y) \leq \frac{2}{3} d_{G}(x, y)$. If $X$ is a symmetric $G$-cone metric space, then $d_{G}(x, y)=2 G(x, y, y) \forall x, y \in X$.

Definition 1.6 [3]. Let $X$ be a $G$-cone metric space and $\left\{x_{n}\right\}$ be a sequence in $X$. We say that $\left\{x_{n}\right\}$ is:

(i) Cauchy sequence if for every $c \in E$, there is $N$ such that $\forall m, n>N, G\left(x_{n}, x_{m}, x_{l}\right) \ll c$.

(ii) Convergent sequence if for every $c \in E$ with $0 \ll c$, there is $\mathrm{N}$ such that $\forall m, n>N, G\left(x_{n}, x_{m}, x\right) \ll c$ for some fixed $x \in X$. Here $\mathrm{x}$ is called the limit of the sequence $\left\{x_{n}\right\}$ and is denoted by $\lim x_{n}=x$ or $x_{n} \rightarrow x$ as $n \rightarrow \infty$.

A $G$-cone metric space $X$ is said to be complete if every Cauchy sequence in $X$ is convergent in $X$.

Proposition 1.7 [3]. Let $X$ be a $G$-cone metric space then the following are equivalent.

(i) $x_{n}$ is convergent to $\mathrm{x}$.

(ii) $G\left(x_{n}, x_{n}, x\right) \rightarrow 0$, as $n \rightarrow \infty$.

(iii) $G\left(x_{n}, x, x\right) \rightarrow 0$, as $n \rightarrow \infty$.

(iv) $G\left(x_{n}, x_{m}, x\right) \rightarrow 0$, as $n, m \rightarrow \infty$.

Lemma 1.8 [3]. Let $X$ be a $G$ cone metric space. $x_{m}, y_{n}$ and $z_{l}$ be sequences in $X$ such that $x_{m} \rightarrow x, y_{n} \rightarrow y$ and $z_{l} \rightarrow z$, then $G\left(x_{m}, y_{n}, z_{l}\right) \rightarrow G(x, y, z)$ as $m, n, l \rightarrow \infty$.

Lemma 1.9 [3]. Let $\left\{x_{n}\right\}$ be a sequence in $G$-cone metric space $X$ and $x \in X$. If $\left\{x_{n}\right\}$ converges to $x$ and $x_{n}$ converges to $\mathrm{y}$, then $x=y$.

Lemma 1.10 [3]. Let $\left\{x_{n}\right\}$ be a sequence in $G$-cone metric space $X$ and if $\left\{x_{n}\right\}$ converges to $x \forall x \in X$, then $G\left(x_{m}, x_{n}, x\right) \rightarrow 0$ as $m, n \rightarrow \infty$.

Lemma 1.11 [3]. Let $\left\{x_{n}\right\}$ be a sequence in $G$-cone metric space $X$ and $x \in X$. If $\left\{x_{n}\right\}$ converges to $x \in X$,then $x_{n}$ is a Cauchy sequence.

Lemma $1.12[3]$. Let $\left\{x_{n}\right\}$ be a sequence in a $G$-cone metric space $X$ and if $x_{n}$ is a Cauchy sequence in $X$, then $G\left(x_{m}, x_{n}, x_{l}\right) \rightarrow 0$, as $m, n, l \rightarrow \infty$.

Theorem 1.13 [11]. Each self map $T$ of a complete metric space $(X, d)$ such that

$$
d(T x, T y) \leq k d(x, y) \quad(x \neq y, 0 \leq k<1)
$$


has a unique fixed point.

Theorem 1.14 [3]. Let $X$ be a complete symmetric $G$-cone metric space and $T: X \rightarrow X$ be a mapping satisfying one of the following conditions:

$$
\begin{aligned}
& G(T x, T y, T z) \leq a G(x, y, z)+b G(x, T x, T x)+c G(y, T y, T y)+d G(z, T z, T z) \\
& \text { or } \\
& G(T x, T y, T z) \leq a G(x, y, z)+b G(x, T x, x)+c G(y, y, T y)+d G(z, z, T z)
\end{aligned}
$$

$\forall x, y, z \in X$, where $0 \leq a+b+c+d<1$. Then $\mathrm{T}$ has a unique fixed point.

Theorem 1.15 [3]. Let $X$ be a complete $G$-cone metric space and $T: X \rightarrow X$ be a mapping satisfying one of the following conditions:

$$
\begin{aligned}
G(T x, T y, T z) & \leq a[G(x, T y, T y)+G(y, T x, T x)] \\
o r & \leq a[G(x, x, T y)+G(y, y, T x)]
\end{aligned}
$$

$\forall x, y, z \in X$, where $a \in\left[0, \frac{1}{2}\right)$. Then $\mathrm{T}$ has a unique fixed point.

Example 1.16 [3].. Let $E=R^{3} ; P=\left\{(x, y, z) \in R^{3}: x, y, z \geq 0\right\}$, and

$X=\left\{(x, 0,0) \in R^{3}: 0 \leq x \leq 1\right\} \bigcup\left\{(0, x, 0) \in R^{3}: 0 \leq x \leq 1\right\} \bigcup\left\{(0,0, x) \in R^{3}: 0 \leq x \leq 1\right\}$.

Define mapping $G: X \times X \times X \rightarrow E$ by

$$
\begin{aligned}
& \begin{array}{l}
G((x, 0,0),(y, 0,0),(z, 0,0)) \\
\quad=\left(\frac{4}{3}(/ x-y /+/ y-z /), / x-y /+/ y-z /,(/ x-y /+/ y-z /)\right), G((0, x, 0),(0, y, 0),(0, z, 0)) \\
=\left((/ x-y /+/ y-z /), \frac{2}{3}(/ x-y /+/ y-z /),(/ x-y /+/ y-z /)\right), G((0,0, x),(0,0, y),(0,0, z)) \\
\quad=\left((/ x-y /+/ y-z /), / x-y /+/ y-z /, \frac{1}{3}(/ x-y /+/ y-z /)\right)
\end{array} \\
& \text { and } \begin{aligned}
G((x, 0,0),(0, y, 0),(0,0, z)) & =G((0,0, z),(0, y, 0),(x, 0,0))=\ldots \\
& =\left(\frac{4}{3} x+y+z, x+\frac{2}{3} y+z, x+y+\frac{1}{3} z\right)
\end{aligned}
\end{aligned}
$$

Then $X$ is a Complete $G$-cone metric space. Let $T: X \rightarrow X$

$T(x, 0,0)=(0, x, 0), T(0, x, 0)=\left(0,0, \frac{1}{3} x\right)$ and $T(0,0, x)=\left(\frac{2}{3} x, 0,0\right)$.

Then $T$ satisfies the contractive condition given in Theorem 3.5 of [3] with constant $a=\frac{3}{4} \in[0,1)$.

Note that $T$ has a unique fixed point $(0,0,0) \in X$.

\section{The Main result}

Theorem 2.1. Let $X$ be a complete symmetric $G$ - cone metric space and $T: X \rightarrow X$ a map for which there exist the real numbers $\mathrm{a}, \mathrm{b}$ and $\mathrm{c}$ satisfying $0 \leq a<1,0 \leq b, c<\frac{1}{2}$, such that for each pair $x, y, z \in X$ at least one of the following is true.

$$
\begin{aligned}
\left(G Z_{1}\right) \quad G(T x, T y, T z) \leq & a G(x, y, z) \\
\left(G Z_{2}\right) \quad G(T x, T y, T z) \leq & b[G(x, T x, T x)+G(y, T y, T y)+G(z, T z, T z)] \\
\left(G Z_{3}\right) \quad G(T x, T y, T z) \leq & c[G(x, T y, T y)+G(x, T z, T z)+G(y, T z, T z) \\
& +G(y, T x, T x)+G(z, T x, T x)+G(z, T y, T y)] .
\end{aligned}
$$

Then $T$ has a unique fixed point.

\section{Proof:}

Considering $\left(G Z_{1}\right)$,

$$
G(T x, T y, T y) \leq a G(x, y, y) .
$$

Considering $\left(G Z_{2}\right)$,

$$
G(T x, T y, T y) \leq b[G(x, T x, T x)+2 G(y, T y, T y)] .
$$

Considering $\left(G Z_{3}\right)$,

$$
G(T x, T y, T y) \leq c[2 G(x, T y, T y)+2 G(y, T x, T x)+2 G(y, T y, T y)] .
$$

By adding (1), (2) and (3),we have

$$
G(T x, T y, T y) \leq q G(x, y, y)+r G(x, T x, T x)+s G(y, T y, T y)+t[G(x, T y, T y)+G(y, T x, T x)]
$$


where $q=\frac{a}{3}, r=\frac{b}{3}, s=\frac{2 b+2 c}{3}$ and $t=\frac{2 c}{3}$.

Suppose $\mathrm{T}$ satisfies condition (4) and $x_{0} \in X$ be an arbitrary point and define the sequence $x_{n}$ by $x_{n}=T^{n} x_{0}$, then we have

$$
\begin{aligned}
G\left(x_{n}, x_{n+1}, x_{n+1}\right) \leq & q G\left(x_{n-1}, x_{n}, x_{n}\right)+r G\left(x_{n-1}, x_{n}, x_{n}\right) \\
& +s G\left(x_{n}, x_{n+1}, x_{n+1}\right)+t G\left(x_{n-1}, x_{n+1}, x_{n+1}\right) \\
{[1-\mathrm{s}-\mathrm{t}] G\left(x_{n}, x_{n+1}, x_{n+1}\right) \leq } & {[\mathrm{q}+\mathrm{r}+\mathrm{t}]\left[G\left(x_{n-1}, x_{n}, x_{n}\right)\right.} \\
\leq & \frac{q+r+t}{1-s-t} G\left(x_{n-1}, x_{n}, x_{n}\right) .
\end{aligned}
$$

Let $j=\frac{q+r+t}{1-s-t}<1$ i.e $q \in[0,1)$,we deduce that

$$
\begin{aligned}
G\left(x_{n}, x_{n+1}, x_{n+1}\right) & \leq j G\left(x_{n-1}, x_{n}, x_{n}\right) \\
& \leq j^{2} G\left(x_{n-2}, x_{n-1}, x_{n-1}\right) \\
& \leq j^{3} G\left(x_{n-3}, x_{n-2}, x_{n-2}\right) \\
& \leq j^{n} G\left(x_{0}, x_{1}, x_{1}\right) .
\end{aligned}
$$

By repeated use of rectangle inequality, we have

$$
\begin{aligned}
G\left(x_{n}, x_{m}, x_{m}\right) \leq & G\left(x_{n}, x_{n+1}, x_{n+1}\right)+G\left(x_{n+1}, x_{n+2}, x_{n+2}\right) \\
& +G\left(x_{n+2}, x_{n+3}, x_{n+3}\right)+\ldots+G\left(x_{m-1}, x_{m}, x_{m}\right) .
\end{aligned}
$$

From (6) and (7), we have

$$
\begin{aligned}
G\left(x_{n}, x_{m}, x_{m}\right) \leq & G\left(x_{n}, x_{n+1}, x_{n+1}\right)+G\left(x_{n+1}, x_{n+2}, x_{n+2}\right) \\
& +G\left(x_{n+2}, x_{n+3}, x_{n+3}\right)+\ldots+G\left(x_{m-1}, x_{m}, x_{m}\right) \\
\leq & {\left[j^{n}+j^{n+1}+j^{n+2}+j^{n+3}+\ldots+j^{m-1}\right] G\left(x_{0}, x_{1}, x_{1}\right) } \\
\leq & j^{n}\left[1+j+j^{2}+j^{3}+j^{4}+\ldots+j^{m-n-1}\right] G\left(x_{0}, x_{1}, x_{1}\right) \\
\leq & j^{n}[1-j]^{-1} G\left(x_{0}, x_{1}, x_{1}\right) \\
\leq & {\left[\frac{j^{n}}{1-j}\right] G\left(x_{0}, x_{1}, x_{1}\right) . }
\end{aligned}
$$

Let $0 \ll c$ be given. Choose $\delta>0$ such that $c+N_{\delta}(0) \subseteq P$, where $N_{\delta}(0)=[y \in E:\|y\|<\delta]$. Also, choose a natural number $N_{1}$ such that $\frac{j^{n}}{1-j} G\left(x_{0}, x_{1}, x_{1}\right) \in N_{\delta}(0), \forall m \geq N_{1}$. Then $\left[\frac{j^{n}}{1-j}\right] G\left(x_{0}, x_{1}, x_{1}\right) \ll c \forall m \geq N_{1}$. i.e. $G\left(x_{n}, x_{m}, x_{l}\right) \ll c \forall m \geq N_{1}$. Therefore $\left\{x_{n}\right\}$ is a $G$-Cauchy Sequence.

Next we will show that $T u=u$. Suppose $T u \neq u$ and $\left\{x_{n}\right\} \rightarrow u$.

$$
\begin{aligned}
G\left(x_{n}, T u, T u\right) \leq & q G\left(x_{n-1}, u, u\right)+r G\left(x_{n-1}, x_{n}, x_{n}\right)+s G(u, T u, T u) \\
& +t\left[G\left(x_{n-1}, T u, T u\right)+G\left(u, x_{n}, x_{n}\right)\right] . \\
G(u, T u, T u) \leq & {[\mathrm{s}+\mathrm{t}] G(u, T u, T u) . }
\end{aligned}
$$

This is a contradiction. So, $T u=u$.

To show the uniqueness, suppose $v \neq u$ is such that $T v=v$, then

$$
\begin{aligned}
G(T u, T v, T v) \leq & q G(u, v, v)+r G(u, T u, T u)+s G(v, T v, T v) \\
& +t[G(u, T v, T v)+G(v, T u, T u)] .
\end{aligned}
$$

Since $T u=u$ and $T v=v$, we have

$$
\begin{aligned}
G(u, v, v) \leq & q G(u, v, v)+r G(u, u, u)+s G(v, v, v) \\
& +t[G(u, v, v)+G(v, u, u)] . \\
G(u, v, v) \leq & {[q+2 t] G(u, v, v) }
\end{aligned}
$$

A contracdiction, which implies that $v=u$. Hence the proof.

\section{References}

[1] M. Abbas and G. Jungek, Common fixed point results for noncommuting mapping without continuity in cone metric spaces, J. Math. Anal. Appl. vol341 (2008), no. 1, pp. 416-420.

[2] M. Abbas and B. E. Rhoades, Fixed and periodic point results in cone metric spaces. Appl. Math. Letter (2008). doi:10.1016/j.akl.07.001.1.

[3] I. Beg, M. Abbas and T. Nazir, Generalized cone metric spaces. Journal of nonlinear science and applications. 3(2010), no1, 21-31. 
[4] V. Berinde, Iterative approximation of fixed points, Efemeride, (2002).

[5] B. C. Dhage, Generalized metric space and mapping with fixed point, Bulletin of the Calcutta Mathematical Society, Vol. 84(1992), 329-336.

[6] B. C. Dhage, On generalized metric space and topological structure II, Pure and Applied Mathematika Sciences, Vol. 40(1994), no.1-2, 37-41, 1994.

[7] Z. Mustafa and B. Sims, A new approach to generalized metric spaces, J. Nonlinear Convex Analysis, Vol.7 (2006), no.2, 289-297.

[8] Z. Mustafa and B. Sims, Fixed point theorems for contractive mappings in complete $G$-metric spaces (2009). doi: $10.1155 / 2009 / 917175$.

[9] Z. Mustafa and B. Sims, Some remarks concerning D-metric spaces. Proceedings of the International Conference on Fixed Point Theory and Applications, Valencia (Spain), July (2003).

[10] Z. Mustafa: A new structure for generalized metric spaces with applications to fixed point theory, PhD thesis, University of Newcastle, Callaghan, Australia (2005).

[11] T. Zamfirescu: Fixed point theorems in metric spaces, Archive for Mathematical Logic (Basel),(1972) 23: 292-298. 